\title{
Involvement of School children in basic life support: Where? How frequently? How did they act?
}

Hideo Inaba ${ }^{1}$, Hisanori Kurosaki ${ }^{1}$, Yukihiro Wato², Yoshio Tanaka ${ }^{1,3}$, Yasuhiro Myojo ${ }^{3}$

1) Department of Circulatory Emergency and Resuscitation Science, Kanazawa University Graduate School of Medicine

2) Department of Emergency Medicine, Kanazawa Medical University

3) Emergency Medical Care Centre, Ishikawa Central Hospital.

Backgrounds and Aims: Basic life support (BLS) education and training for school children are very active in many countries including Japan. This study aimed to investigate how frequently school children are involved in BLS for cases with emergency medical service (EMS)unwitnessed out-of-hospital cardiac arrest (OHCA) and how they acted when they witness or found a victim of OHCA.

Methods: Extended Database for 5,478 EMS-unwitnessed OHCA that were prospectively collected during the period of 2011-2016 were retrospectively analysed. School children included students in elementary, junior and senior high schools, who are 6-18 years old in Japan.

Results:

Ba Involvement of school children in detection and recognition of OHCA was extremely rare: 88 $(1.6 \%)$ of 5,478 EMS-unwitnessed OHCAs. Major actions in which school children were involved were detection of cardiac arrest $(96.6 \%)$, call for help $(62.5 \%)$ and emergency call $(36.4 \%)$. School children were rarely involved in bystander CPR (18.2\%). OHCA was witnessed by school children in $30(34.1 \%)$ cases.
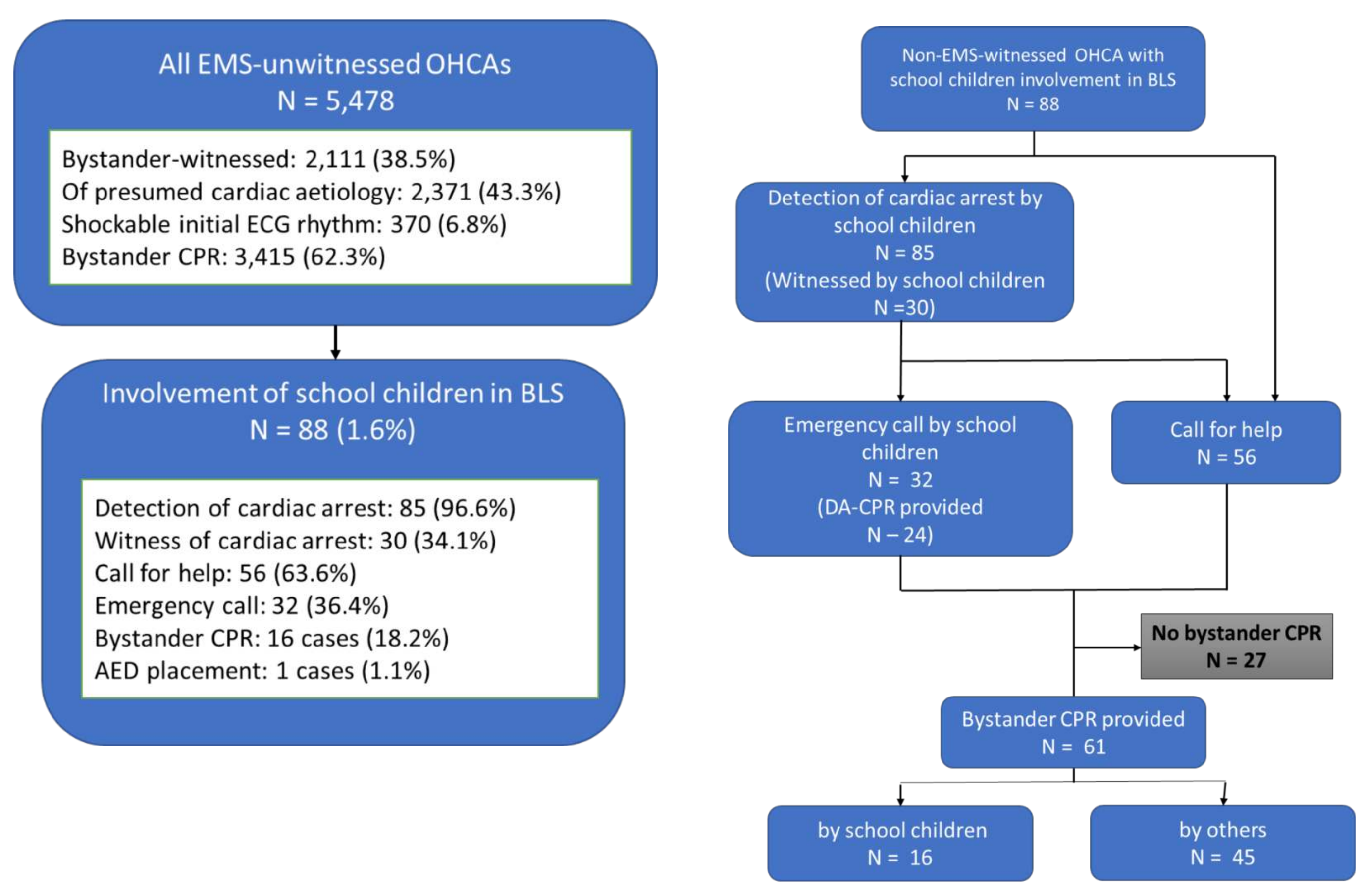

Fig.1 Overview
When school children were involved in BLS, locations of OHCA were more frequently home $(70$, $80.0 \%)$ and school $(6,6.8 \%)$. OHCA was more frequently caused by suicide attempt in $12(13.8 \%)$ cases. In $32(36.4 \%)$ cases, school children placed emergency 119 calls as the first action by themselves. Dispatchers instructed cardiopulmonary resuscitation (CPR) to school children in 8 cases. In other cases, emergency calls were largely delayed when school children dialed other numbers or left the scene to seek help. Dispatchers instructed cardiopulmonary resuscitation (CPR) to school children in 24 cases. Although bystander CPR were provided in 61 (69.3\%) cases, school children were rarely involved in bystander CPR (18 cases) and AED placement (1 case).

Conclusions: Involvement of School children in basic life support is extremely rare. Emergency calls are delayed when school children act to seek help. Because considerable number of OHCAs were caused by suicide attempts and serious injuries, mental care to school children involved in BLS may be necessary.

Table 1 Characteristics of OHCA and outcomes

\begin{tabular}{|c|c|c|c|}
\hline \multirow{2}{*}{$\begin{array}{l}\text { Characteristics of OHCA } \\
\text { And outcomes }\end{array}$} & \multicolumn{2}{|c|}{ Involvement of school children in BLS } & \multirow[t]{2}{*}{$P$ values } \\
\hline & $\begin{array}{l}\text { Involved } \\
\mathrm{N}=88\end{array}$ & $\begin{array}{l}\text { Not involved } \\
N=5,478\end{array}$ & \\
\hline Child victims & $22(25 \%)$ & $46(0.9 \%)$ & $P<0.01$ \\
\hline Location-home & 70 (80.0\%) & $3,455(64.1 \%)$ & $P<0.01$ \\
\hline Location-school & $6(6.8 \%)$ & $3(0.1 \%)$ & $\mathrm{P}<0.01$ \\
\hline Of presumed cardiac & $32(36.4 \%)$ & $2,339(43.4 \%)$ & $P=0.18$ \\
\hline Suicide attempt & $12(13.6 \%)$ & $267(5.0 \%)$ & $P<0.01$ \\
\hline Shockable initial rhythm & $8(9.1 \%)$ & $362(6.7 \%)$ & $P=0.38$ \\
\hline \multicolumn{4}{|l|}{ Outcomes } \\
\hline 1-M survival & $6(6.8 \%)$ & $274(5.1 \%)$ & $P=0.46$ \\
\hline $\begin{array}{l}\text { Neurologically favourable } 1-Y \\
\text { survival }\end{array}$ & $2(2.3 \%)$ & $136(2.5 \%)$ & $P=0.88$ \\
\hline
\end{tabular}
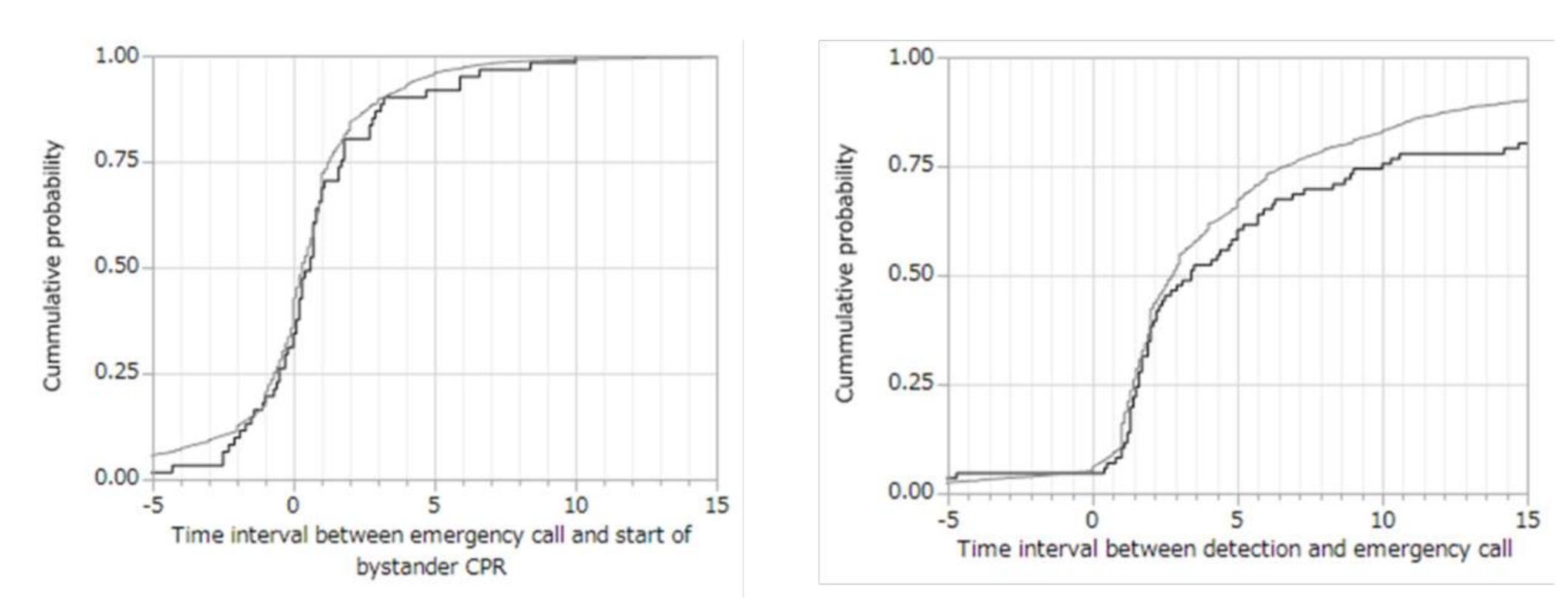

Fig. 3 Time factors 